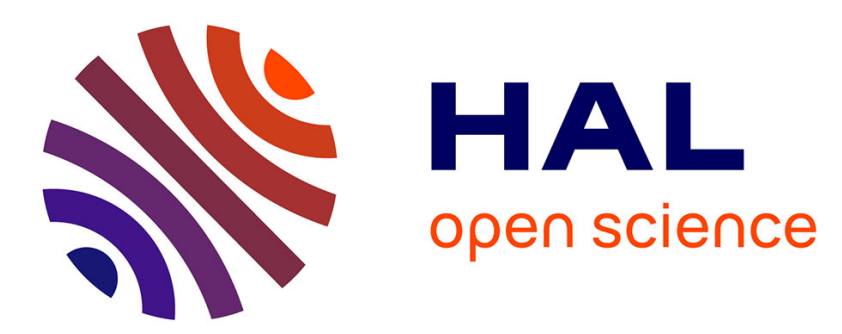

\title{
Compressive Deformation and Failure of Trabecular Structures in A Turtle Shell
}

Edward Ampaw, Tunji Adetayo Owoseni, Fen Du, Nelson Pinilla, John

Obayemi, Jingjie Hu, Pierre-Marie Nigay, Ange Nzihou, Vanessa Uzonwanne, Zebaze Kana, et al.

\section{To cite this version:}

Edward Ampaw, Tunji Adetayo Owoseni, Fen Du, Nelson Pinilla, John Obayemi, et al.. Compressive Deformation and Failure of Trabecular Structures in A Turtle Shell. Acta Biomaterialia, 2019, 97, pp.535-543. 10.1016/j.actbio.2019.07.023 . hal-02263640

\section{HAL Id: hal-02263640 https://imt-mines-albi.hal.science/hal-02263640}

Submitted on 22 Oct 2020

HAL is a multi-disciplinary open access archive for the deposit and dissemination of scientific research documents, whether they are published or not. The documents may come from teaching and research institutions in France or abroad, or from public or private research centers.
L'archive ouverte pluridisciplinaire HAL, est destinée au dépôt et à la diffusion de documents scientifiques de niveau recherche, publiés ou non, émanant des établissements d'enseignement et de recherche français ou étrangers, des laboratoires publics ou privés. 


\title{
Compressive deformation and failure of trabecular structures in a turtle shell
}

\author{
Edward Ampaw ${ }^{\mathrm{a}, \mathrm{c}, 1}$, Tunji Adetayo Owoseni ${ }^{\mathrm{a}, 1}$, Fen Du ${ }^{\mathrm{b}, 1}$, Nelson Pinilla ${ }^{\mathrm{d}}$, John Obayemi ${ }^{\mathrm{g}}$, \\ Jingjie $\mathrm{Hu}^{\mathrm{d}}$, Pierre-Marie Nigay ${ }^{\mathrm{d}, \mathrm{g}}$, Ange Nzihou ${ }^{\mathrm{e}}$, Vanessa Uzonwanne ${ }^{\mathrm{g}}$, \\ Martiale Gaetan Zebaze-Kana ${ }^{\mathrm{a}}$, Mandar Dewoolkar ${ }^{\mathrm{f}}$, Ting $\operatorname{Tan}^{\mathrm{f}}$, Winston Soboyejo ${ }^{\mathrm{d}, \mathrm{g}, *}$
}

${ }^{a}$ Department of Materials Science and Engineering, African University of Science and Technology, Nigeria

${ }^{\mathrm{b}}$ Department of Mechanical Engineering, Vermont Technical College, Randolph Center, VT 05061, USA

${ }^{\mathrm{c}}$ Department of Mechanical Engineering, Koforidua Technical University, Koforidua, Ghana

${ }^{\mathrm{d}}$ Department of Mechanical and Aerospace Engineering, Princeton University, Princeton, NJ 08540, USA

${ }^{\mathrm{e}}$ Department of Chemical Engineering, Université de Toulouse, Mines Albi, CNRS UMR 5302, Centre RAPSODEE, F-81013 Albi Cedex 09, France

${ }^{\mathrm{f}}$ Department of Civil and Environmental Engineering, University of Vermont, Burlington, VT 05405, USA

${ }^{\mathrm{g}}$ Department of Mechanical Engineering, Worcester Polytechnic Institute, MA 01609, USA

Keywords:

Turtle shell

Trabecular bone

Compressive deformation

Failure

Foam structure

\begin{abstract}
A B S T R A C T
Turtle shells comprising of cortical and trabecular bones exhibit intriguing mechanical properties. In this work, compression tests were performed using specimens made from the carapace of Kinixys erosa turtle. A combination of imaging techniques and mechanical testing were employed to examine the responses of hierarchical microstructures of turtle shell under compression. Finite element models produced from microCT-scanned microstructures and analytical foam structure models were then used to elucidate local responses of trabecular bones deformed under compression. The results reveal the contributions from micro-strut bending and stress concentrations to the fractural mechanisms of trabecular bone structures. The porous structures of turtle shells could be an excellent prototype for the bioinspired design of deformation-resistant structures.
\end{abstract}

\section{Statement of Significance}

In this study, a combination of analytical, computational models and experiments is used to study the underlying mechanisms that contribute to the compressive deformation of a Kinixys erosa turtle shell between the nano-, micro- and macro-scales. The proposed work shows that the turtle shell structures can be analyzed as sandwich structures that have the capacity to concentrate deformation and stresses within the trabecular bones, which enables significant energy absorption during compressive deformation. Then, the trends in the deformation characteristics and the strengths of the trabecular bone segments are well predicted by the four-strut model, which captures the effects of variations in strut length, thickness and orientation that are related to microstructural uncertainties of the turtle shells. The above results also suggest that the model may be used to guide the bioinspired design of sandwich porous structures that mimic the properties of the cortical and trabecular bone segments of turtle shells under a range of loading conditions.

\footnotetext{
* Corresponding author at: Department of Mechanical and Aerospace Engineering, Princeton University, Princeton, NJ 08540, USA.

E-mail address: wsoboyejo@wpi.edu (W. Soboyejo).

${ }^{1}$ Edward Ampaw, Tunji Owoseni and Fen Du contributed equally to this work.
}

\section{Introduction}

Turtle shells are natural materials with excellent mechanical properties that shield turtles from predators over thousands of years [1]. They also regulate the temperature, and serve as a reservoir of fats and water [1-5]. Recent work has suggested that the turtle shell might have evolved as an adaption to life underground [4]. In any case, the attractive combinations of different functions 
have stimulated recent studies of the mechanical performance of structures [6-9] or components of turtle shells [5,10-13].

The turtle shell comprises a bi-layered skin that consists of keratin and collagen [10], a sandwiched bone structure including external cortical bones and an internal trabecular bone structure $[1,11]$. Shelef and Bar-On [10] have used nanoindentation techniques to measure the graded elastic moduli of the red ear turtle skin (Trachemys elegans) $[2,14]$. Finite element results show that the bi-layered skin structure protects the inner bones from localized impact by reducing the stress concentrations via structural gradients and extensive near surface plasticity. Chen et al. [15] have used Atomic Force Microscopy (AFM) experiments to characterize the elastic moduli and morphologies of the epidermal skin of red ear turtle shell. They reported that the excellent mechanical properties of the skin are due to ordered hierarchical composites formed by nanoplatelets comprising calcium phosphate and calcium sulfate polycrystals dispersed in the keratin. Balani et al. [16] have used similar laminate models to study the fractural properties of a dry turtle shell (Chelydra serpentina), which includes both the epidermal skin and sandwiched bone structures. The studies have identified lamellae pullout and carbonaceous fiber bridging as the primary toughening mechanisms. The elastic moduli and hardnesses of the epidermal skin or bone layers were found to vary between different turtles [1].

Magwene and Socha have studied [17] the mechanical properties of carapaces, isolated bones and sutures of four types of turtles, i.e., Trachemys scripta, Malaclemys terrapin, Chrysemys picta, and Terrapene Carolina. The entire carapaces were loaded under compression using surface and point loads, whereas the bones and sutures were loaded under three-point bending. In the case of the carapaces, small grooves were introduced into the bone by the sulci (margins of the epidermal scutes), resulting in weakness points within the shell. However, although the sutures were weaker than bones on the flexural strength, they absorbed similar amounts of energy due to the higher failure strains. Achrai and Wagner [11] have measured the elastic moduli and hardnesses of the skin, and the carapace bones of red ear turtles. They reported that the epidermal skin served as the initial shock absorbing layer during impact, while the sandwiched bone structure worked together to further resist impact [18]. Further studies [19,20] have also been carried out to investigate the static and cyclic bending behavior of turtle shells at different locations and orientations. Under static bending, sutures were weaker, but tougher than ribs. Under cyclic bending, sutures were less durable than ribs. The respective alternation of soft and hard rib-and-suture structures resulted in the fatigue resistance of carapace were better than that of individual ribs or sutures.

Damiens et al. [21] and Rhee et al. [5] have studied the compressive behavior of the box turtle shell (Terrapene Carolina). The resulting stress-strain curves exhibited three distinctive stages: (i) a linear elastic regime, (ii) a perfectively inelastic regime, and (iii) a densification regime in which micro-buckling and compaction occurred in the trabecular bone structures [22-24]. Jongpairojcosi and Jearanaisilawong [25] have studied the mechanical properties of the sulcate tortoise (Centrochelys sulcata) carapace under quasi-static compression or bending loads. Their work showed that porosity and structural compositions are essential to the deformation characteristics and strengths of the sandwiched layered structures. Zhang et al. [26] have investigated the deformation under tension, bending and impact wear behavior of a fresh water turtle shell at different hydration levels. As the hydration period increased, the absorbed energy during impact increased. As the number of impact cycles increased, the damage size increased. They concluded that the water molecules inside the porous structures acted as a buffer to reduce the influence from the impact loads.
Despite prior efforts, there is still a need of using multi-scale experiments and models to provide integrated insights into the deformation and fracture of turtle shell structures between the nano-, micro- and macro-scales. The objective of this study is to study the underlying mechanisms that contribute to the compressive deformation of a Kinixys erosa turtle shell using a combination of analytical/computational models and experiments at different physical scales. First, we performed X-ray diffraction (XRD), scanning electron microscopy (SEM) and nanoindentation experiments to study the structural and mechanical properties of the bone layers in the Kinixys erosa turtle shell. A combination of micro-computed tomography (microCT) observations and scanning electron microscopy was then used to study the turtle shell structures consisting of layers with cortical and trabecular bone structures. The insights from the observation and the multi-scale measurements of strut, foam and sandwich properties were used to guide the analytical and finite element models for the prediction of deformation, stress distributions and failure in Kinixys erosa turtle shells. The implications of the results are then discussed for the bioinspired design of cellular materials.

\section{Materials and methods}

\subsection{Sample preparations}

A Kinixys erosa tortoise shell was obtained from Department of Botany and Zoology at the University of Ibadan, Ibadan, Nigeria. The carapace was cleaned from soft tissues before specimens were prepared for compression tests. Specimens with dimensions of $7 \mathrm{~mm} \times 9 \mathrm{~mm} \times 8 \mathrm{~mm}$ were cut from different locations of the turtle shell, including the external cortical bone, a foam-like trabecular bone, and an internal cortical bone. Specimens with trabecular sections between $0.63,0.83,1.32$ and $2.00 \mathrm{~mm}$ were prepared for the compression tests.

\subsection{Nanoindentation}

A Hysitron TriboIndenter ${ }^{\circledR}$ (Hysitron, Minneapolis, MN, USA) was used to measure the elastic moduli of cortical and trabecular bones through nanoindentations $[27,28]$, in which specimens with the same thickness were used. A Berkovich diamond tip, i.e., a three-sided pyramid with the angle of $142.3^{\circ}$ and the radius of $\sim 150 \mathrm{~nm}$, was used to indent the bone specimens. The standard diamond tip has an elastic modulus of $1140 \mathrm{GPa}$ and a Poisson's ratio of 0.07 . The tip was calibrated using a standard fused quartz sample for required depths. Indentation tests were performed at a loading rate of $200 \mu \mathrm{N}$ per second up to a maximum load of $5000 \mu \mathrm{N}$, and the indented depth was $\sim 850 \mathrm{~nm}$. The Oliver-Pharr method was used in the software to calculate the elastic moduli from the unloading curves.

\subsection{X-ray diffraction}

X-ray diffraction analysis was also performed for turtle bones using an Empyrean multipurpose diffractometer (PANanalytical, Royston, UK). Turtle bone powders were pulverized using mortar and pestle. Powder diffraction patterns were collected at $45 \mathrm{kV}$ and $40 \mathrm{~mA}$ using a copper anode material. Scans were carried out with the $2 \theta$ angle ranging from $10^{\circ}$ to $110^{\circ}$ at $0.0167^{\circ}$ per second.

\subsection{Scanning electron microscopy}

The surfaces of the turtle shell specimens before compression were examined using a FEI Quanta 200 Environmental Scanning Electronic Microscope (FEI, Hillsboro, OR, USA). The SEM images 
were obtained at operating voltages $\sim 15$ to $20 \mathrm{kV}$, and at pressures between 8.3 and 9.8 Torr. Energy Dispersive Spectroscopy (EDS) analyses were then used to characterize the distributions of elements within the turtle shell specimens.

\subsection{X-ray microtomography}

X-ray microtomography (microcT) was used to examine the microstructure of the turtle bones before and after failure. The microCT scans were performed using a Skycan 1173 X-ray microtomographer (Microphotonics, Allentown, PA, USA) that was operated at a voltage of $45 \mathrm{kV}$ and a current of $160 \mu \mathrm{A}$ without any filters. Each scan was performed with a resolution of $\sim 6.0 \mu \mathrm{m}$ for $13.5 \mathrm{~h}$. Microstructural images obtained from the microCT scans were digitized for subsequent use in the finite element models.

\subsection{Compression tests}

The deformation characteristics and mechanical properties of the turtle shell specimens were studied under monotonic loading $[28,29]$ using a TIRA test-2810 Universal testing machine (TIRA $\mathrm{GmbH}$, Schalkau, Germany). Three replicas were tested for specimens with similar lengths of trabecular sections. The specimens were placed between two smooth and flattened plates by aligning the load direction perpendicular to the laminates of sandwiched bones. Quasi-static compression tests were conducted at the displacement rate of $0.1 \mathrm{~mm}$ per minute, until the densification stage was reached.

\section{Modeling}

\subsection{Finite element modeling}

Mathematical modeling was carried out using the ABAQUS ${ }^{\mathrm{TM}}$ software package (Dassault Systems, Pawtucket, RI, USA). Models of the porous cortical and trabecular bone structures were created using digitized images of microCT scans (Fig. 4a). The CT images were first processed by SolidWorks software (Dassault Systems, MA, USA) to generate geometrical models, which were then converted into finite element meshes for ABAQUS ${ }^{\mathrm{TM}}$ software. Each finite element model was meshed using $\sim 400,000$ four-node linear tetrahedral elements (C3D4). The elastic moduli measured in the nanoindentation tests were assigned to the cortical and trabecular bones, respectively. The Poisson's ratio of 0.3 was assigned to both cortical and trabecular bones of the turtle shell. For boundary conditions, the bottom surface was fixed, whereas the top surface was applied with the compression. In the static module of ABAQUS ${ }^{\mathrm{TM}}$, the direct solver based on the full Newton technique was used with a maximum of 100 increments.

\subsection{Four-strut foam model}

A four-strut model $[22,30,31]$ has been proposed to simulate the compressive deformation of foam structures. In this fourstrut unit (Fig. 5a-d), strut 1 (AB) stands on node $B$, which is connected by three struts $2(\mathrm{BC}), 3(\mathrm{BD})$ and $4(\mathrm{BE})$ in the base. Each strut is characterized by three parameters, i.e., the length, $l_{i}$, cross section area, $A_{i}$, and the orientation of each strut $\alpha_{i}$, which is defined by the angle between each strut and z-axis, while the angles between each of the two struts in the base is $\beta_{i}$. It is assumed that the length of strut 1 is $l_{1}$, while the three struts in the base have the same length $l_{2}$. Strut 1 is, therefore oriented at an angle of $\alpha_{1}$, to the z-axis. The three struts in the base have the same angles with respect to z-axis, i.e., $\alpha_{2}=\alpha_{3}=\alpha_{4}=\alpha$. The angles between each two struts in the base are the same, i.e., $\beta_{1}=\beta_{2}=\beta_{3}$.
The edge length of each square cross section is the same, i.e., $t$. Each strut $(2,3,4)$ in the base sustains one third of the compression of strut 1 . The effective compressive stiffness of the structure unit, $E_{f}$, is obtained from [22]:

$E_{f}=\frac{27 \sqrt{3}}{16} \frac{(\kappa+\cos \alpha)^{3}}{(\kappa+3)^{2}} \tau \rho^{2} E_{s}$

where $\kappa$ is the length ratio of $l_{1}$ to $l_{2}$, i.e., $l_{1} / l_{2}, \tau$ is the occupation coefficient, $\rho$ is the relative density, and $E_{s}$ is the Young's moduli of the solid.

In the four-strut model, the compressive failure of foam is determined by the competition between the plastic bending of the struts 2, 3, 4 in the base, and the plastic bending of strut 1 . The upper and lower bound plastic collapse strengths due to the plastic bending of struts 2, 3, 4 in the base, i.e., $\sigma_{c r, \min }^{b d}$ and $\sigma_{c r, \max }^{b d}$, are given by [22]:

$\sigma_{c r, \min }^{b d}=\frac{3^{\frac{7}{4}}}{4}\left(\frac{1}{3 f}\right)\left(\frac{\kappa+\cos \alpha}{\kappa+3}\right)^{\frac{3}{2}} \tau^{\frac{1}{2}} \rho^{\frac{3}{2}} \sigma_{Y S}$

$\sigma_{c r, \max }^{b d}=\frac{3^{\frac{7}{4}}}{4}\left(\frac{\kappa+\cos \alpha}{\kappa+3}\right)^{\frac{3}{2}} \tau^{\frac{1}{2}} \rho^{\frac{3}{2}} \sigma_{Y S}$

If the strut 1 is at an inclined angle to the z-axis, the critical plastic collapse strength, $\sigma_{c r}^{b 1}$, is obtained as:

$\sigma_{c r}^{b 1}=\frac{3^{\frac{3}{4}}}{4}\left(\frac{\kappa+\cos \alpha}{\kappa+3}\right)^{\frac{3}{2}}\left(\frac{1}{\kappa}\right)\left(\frac{\sin \alpha}{\sin \alpha_{1}}\right) \tau^{\frac{1}{2}} \rho^{\frac{3}{2}} \sigma_{Y S}$

where $f$ is the fraction constant, $\sigma_{Y S}$ is the yield strength of the solid, and $\alpha_{1}$ is the angle between strut 1 and the z-axis [22]. The actual spectrum of collapse strengths is defined by the critical strengths obtained from by Eqs. (2) and (3) for the plastic bending of struts $2,3,4$ in the base, or calculated from Eq. (1) for the plastic bending of strut 1.

\subsection{Gibson-Ashby model}

Gibson and Ashby [32,33] have used the cubic models to estimate the stiffnesses and strengths of three-dimensional cellular foams. In open-cell foams, the cell edges deform primarily by bending. The Young's moduli, $E_{f}$, of the foams are given by [32]:

$E_{f}=C_{1} \rho^{2} E_{s}$

where $C_{1}$ is a constant $\left(C_{1} \approx 1\right), \rho$ is the density and $E_{S}$ is the Young's modulus of the dense solid.

In the case of elastic-plastic materials, the plateau stresses of the foams occur when the cells begin to collapse plastically. For open-cell foams, the plastic collapse strength, $\sigma_{f}$, is given by [32,33]:

$\sigma_{f}=C_{2} \rho^{\frac{3}{2}} \sigma_{Y S}$

where $C_{2}$ is a constant that is related to the cell geometry $\left(C_{2} \approx 0.3\right)$.

\section{Results and discussion}

\subsection{The turtle structure}

A Kinixys erosa tortoise shell was shown in Fig. 1a and b. The microstructures of the turtle shell structures were revealed by the microCT scans in Fig. 1c-f, in which images are presented for undeformed cortical and trabecular structures (Fig. 1c and e) and deformed trabecular structures (Fig. 1d and f). The microCT analysis disclosed that the porosities of the external and internal cortical bones were $\sim 3.2 \%$ and $\sim 3.1 \%$, respectively. The porosity of the 
(a)

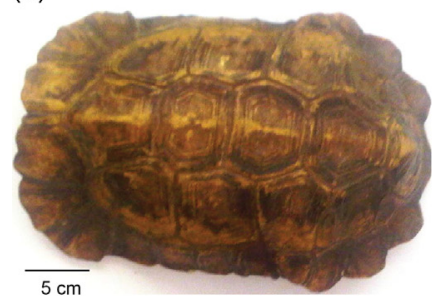

(b)

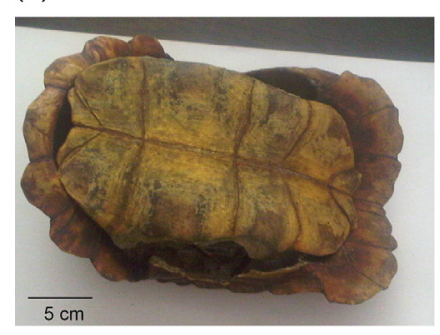

(c)

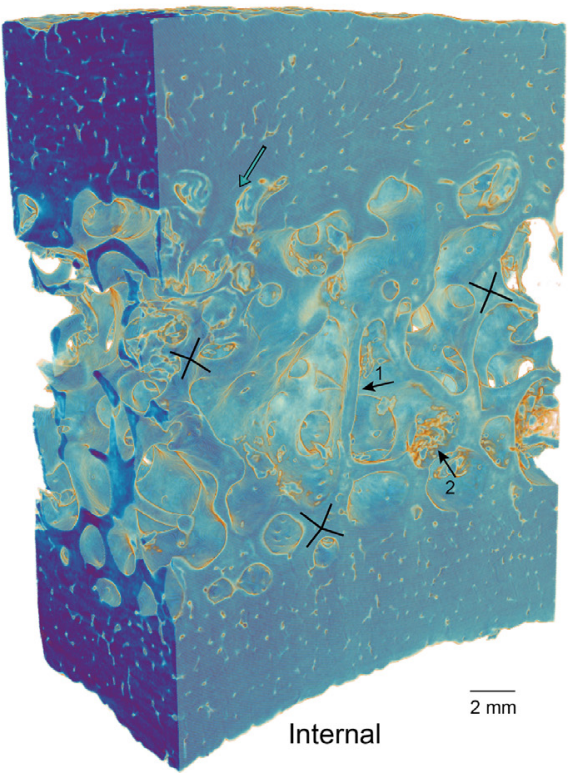

(d)

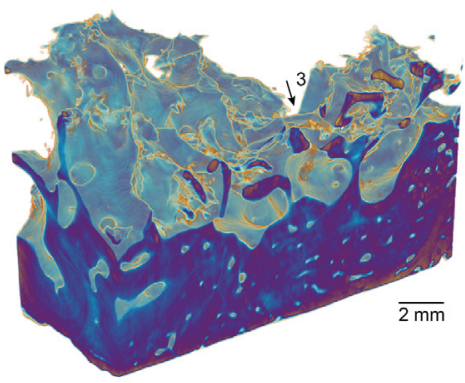

(e)

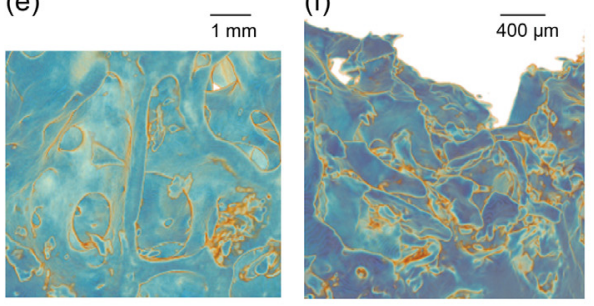

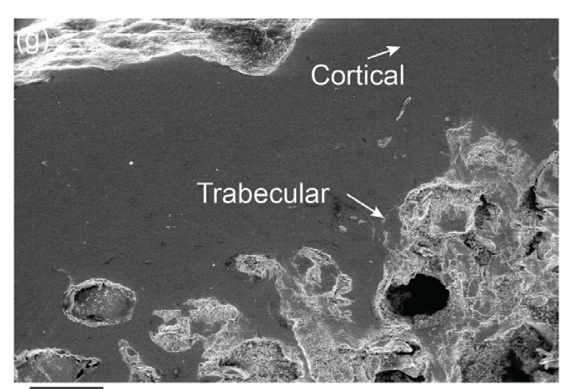

$\overline{500 \mu \mathrm{m}}$
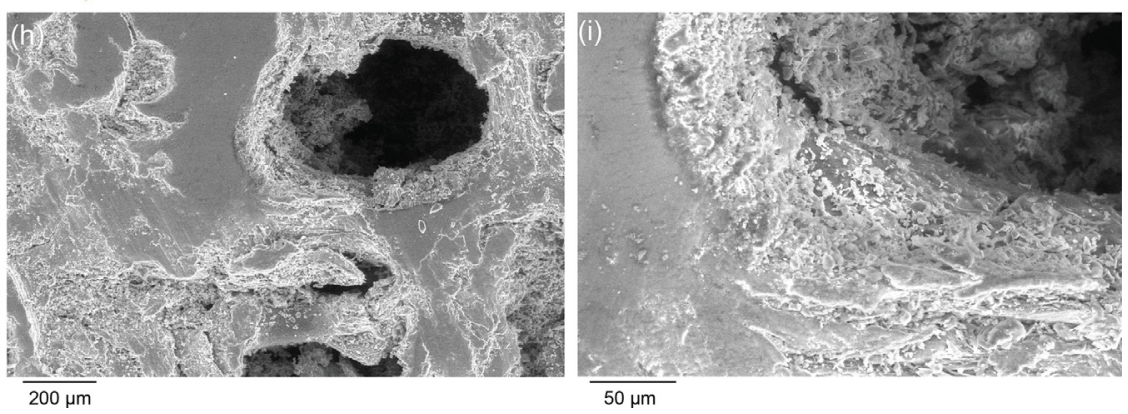

Fig. 1. Photographs of the Kinixys erosa tortoise shell (a) Top view. (b) Bottom view. MicrocT images of the sandwiched cortical-trabecular bone structure in the turtle shell (c) Before compression. (d) After compression. (e) Detailed view of the micro-struts around regions pointed by arrow 1. (f) Detailed view of the collapsed micro-struts in trabecular bones pointed by arrow 2. SEM images of the turtle shell regions pointed by the empty arrow (g) Overview of the cross-section exhibits the transition from cortical bones to trabecular bones. (h) and (i) Detailed views of a hole in the trabecular bone.

trabecular bones was $\sim 55.7 \%$. The images reveal porous structures with large intertrabecular space in trabecular bones, and small micro-scale pores in cortical bones. Before compression, the porous structures in trabecular bones smoothly connected the top and bottom cortical bones. Fibrous struts extended both vertically and horizontally to generate a foam-like structure with substantial amount of pores in between. A detailed view (Fig. 1e) of the microstruts (labelled by arrow 1 in Fig. 1c) shows that the tiny columns are aligned to resist compression. Four-strut units were also found within the porous network (Fig. 1c). These correspond to the unit cells that were used to model the deformation of the trabecular bone structures (Fig. 5). Furthermore, some rough surface regimes (labelled by arrow 2 in Fig. 1c) were also observed in trabecular bone.

Typical SEM images of the undeformed struts in the porous structures are presented in Fig. 1g-i. Away from the top surface, the solid cortical bones gradually transformed into porous trabecular bones with isolated or interconnected holes (Fig. $1 \mathrm{~g}$ and $\mathrm{h}$ ). A detail view showed that the rough inner surface of a trabecular hole was covered by angular and packed particles (Fig. 1i). After compression, the micro-struts in the trabecular bone segments were no longer stretched vertically as they were before. Instead, collapsed trabecular micro-struts were observed to form pores around the fracture surfaces (Fig. 1d). Furthermore, small and distributed pores remained open in the cortical bones (Fig. 1d). Hence, the microCT characterization revealed that the final failure of the sandwich bone structures was associated with the collapse of micro-struts inside trabecular bones in the turtle shell structure.

\subsection{Material characterization}

The X-ray diffraction analysis revealed phases in the carapace bone (Fig. 2a). The carapace bone exhibited a widened peak for $2 \theta$ between $31^{\circ}$ and $33^{\circ}$, resulting from the superposition of the highest ( 211 ) peak of hydroxyapatite (HA) at $31.61^{\circ}$, the second

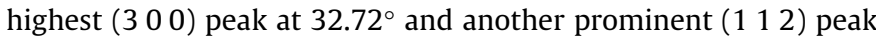
at $32.22^{\circ}$ [34-36]. Lower intensity peaks of HA were also detected based on the small humps between $46^{\circ}$ and $54^{\circ}$ [36]. These results confirmed the presence of hydroxyapatite in the carapace, which is a major component of bone. Semi-quantitative Energy Dispersive Spectroscopic maps of the structural compositions (Fig. 2b-e) also revealed that the surfaces contained calcium, phosphorous, carbon, and oxygen. These are mostly elements that are found in the bone of the turtle carapace.

\subsection{Compressive deformation and failure}

The Young's moduli measured corresponding to the actual unloading segment of the load-deflection curves [34] were $13.9 \pm 0.9 \mathrm{GPa}$ for the external cortical bone, $12.1 \pm 1.0 \mathrm{GPa}$ for the internal cortical bone, and $4.0 \pm 2.1 \mathrm{GPa}$ for the trabecular bone. These are consistent with prior reports in the literature [1]. Hence, 


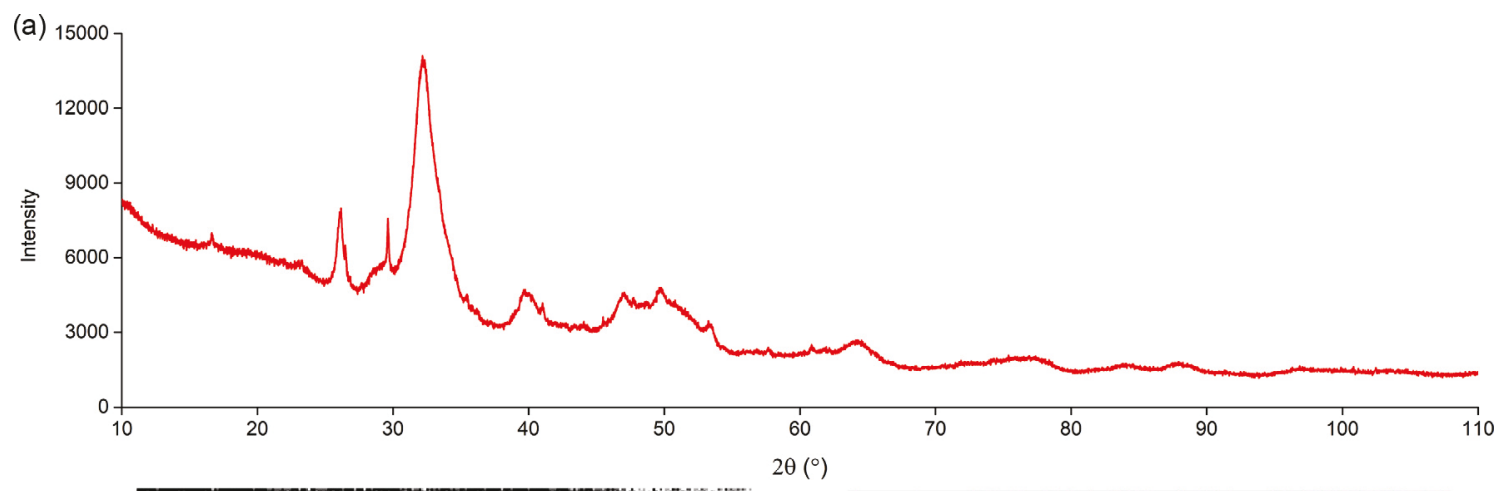

(b) $\mathrm{Ca}$

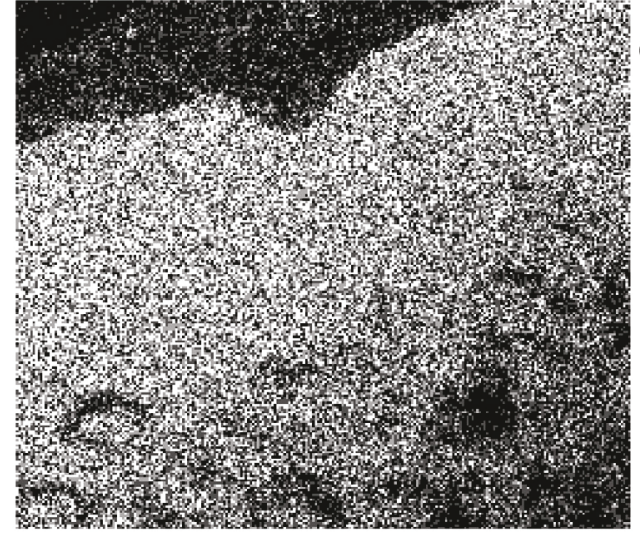

(c) $P$

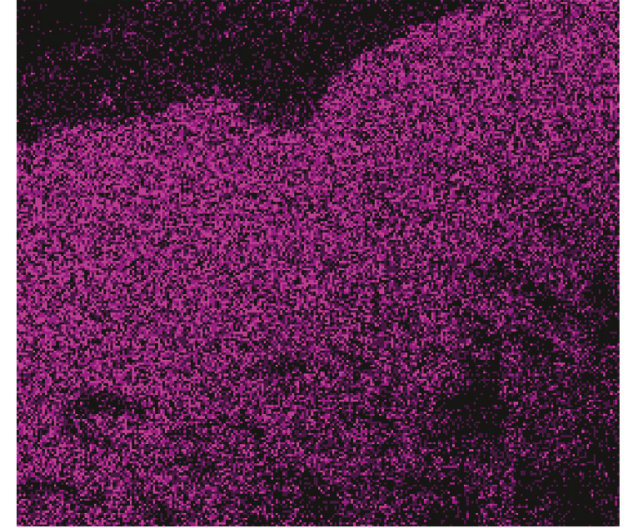

$2 \mathrm{~mm}$

(d) $\mathrm{C}$

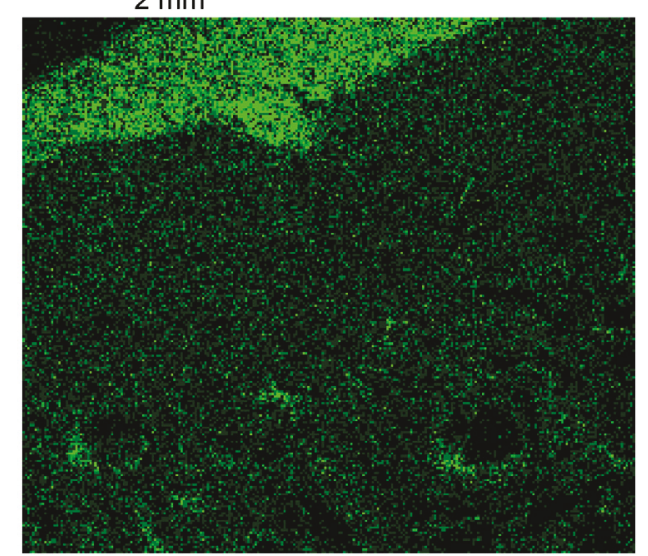

(e) 0

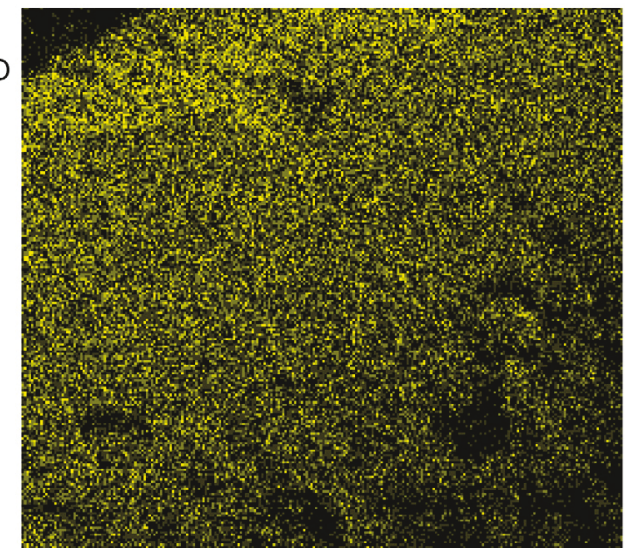

Fig. 2. (a) XRD results of the turtle bone. Element distributions of the turtle shell (b) Ca. (c) P. (d) C. (e) O.

the trabecular bone components are more compliant than the cortical bone segments.

Typical compressive stress-strain curves of the specimen under monotonic loading are presented in Fig. $3 \mathrm{a}$ and $\mathrm{b}$. The curves were from specimens with trabecular bones thickness between 0.63 and $2.00 \mathrm{~mm}$. The specimens containing the thicker trabeculae exhibited a three-stage deformation behavior that included a linear elastic regime, a plateau regime in which the stress remounted almost constant, and a final densification regime in which the stress increased monotonically as the porous structure was crushed $[32,33]$. In the case of the foams with $0.63 \mathrm{~mm}$ thick struts, the slope of the stress-strain curves was not flat in the intermediate regime probably due to the small trabecular bone section (Fig. 3a).

In all cases, the deformation in regime 1 was associated with the elastic bending of the struts in the trabecular structures (Fig. 3b). This was followed by regime 2 in which plastic hinges were formed along localized slip bands that propagated along the specimen. Finally, deformation in regime 3 occurred by the plastic collapse and densification of the porous trabecular structure.
Fig. 3d shows that the toughness of turtle specimens varies at different thickness of the trabecular structure. ANOVA analyses with $95 \%$ confidence have been performed to compare the elastic moduli, plastic collapse strengths and toughnesses for specimens with different trabecular bone sections. Results showed that there were clear differences of elastic moduli and toughness between these groups, whereas the collapse strengths were similar among these groups.

\subsection{Stress contours}

The finite element models of the porous structures (Fig. 4a-d) provided insights into the stress distributions within the turtle shell bone structures. The stress distributions in the top and bottom cortical bones were relatively uniform compare to those in the trabecular bones. Furthermore, at the joints between the cortical bones and the trabecular bones (labelled by arrow 1 in Fig. 4b), the stresses increased gradually from lower to higher levels, with clear gradients (Fig. 4c). In contrast, the stress distributions in the trabecular bones varied significantly within the different struts, 

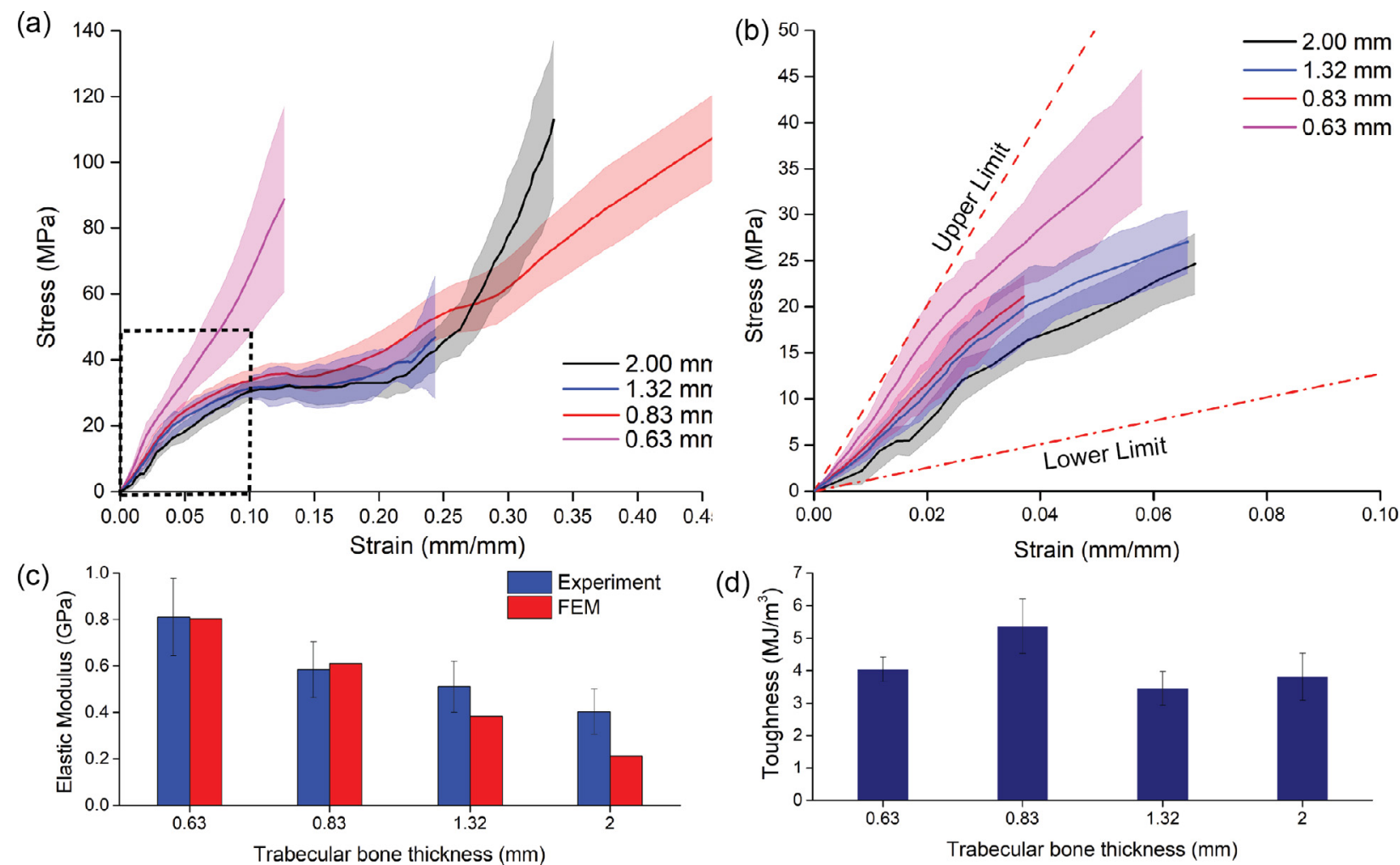

Fig. 3. (a) Compressive stress-strain curves of sandwiched bone specimens with different thicknesses of trabecular bones. The solid lines represent the average, whereas the shaded spectrums represent the standard deviations. (b) The linear regime enclosed in the dash box was magnified. Limits predicted from the finite element models were compared with the elastic stages of stress-strain curves during monotonic compression tests. (c) Comparison between predicted elastic moduli and the experimental measurements of trabecular bones at different thicknesses. (d) Toughness of trabecular bones at different thicknesses.

(a)

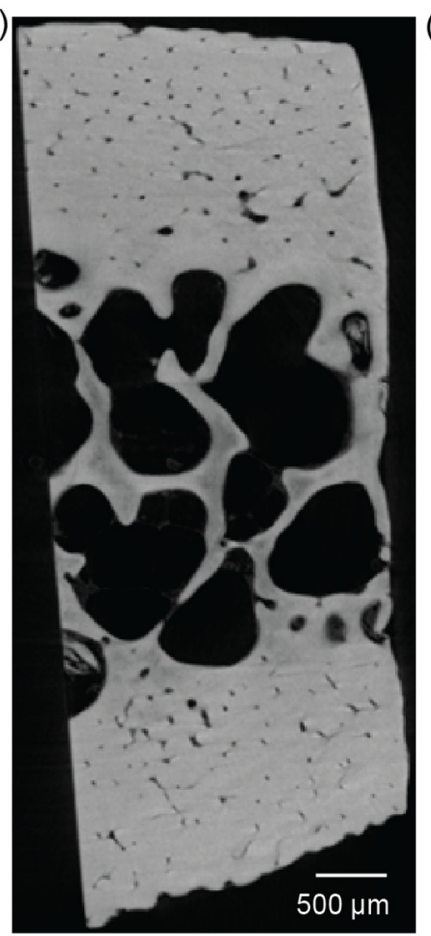

(b)

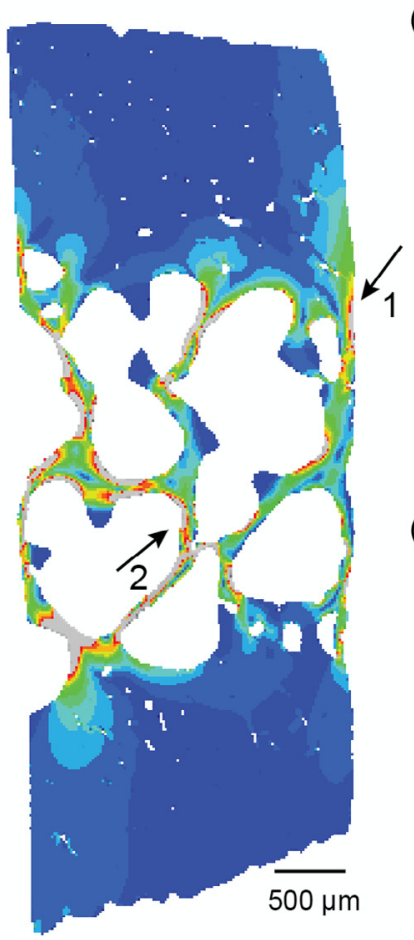

(c)
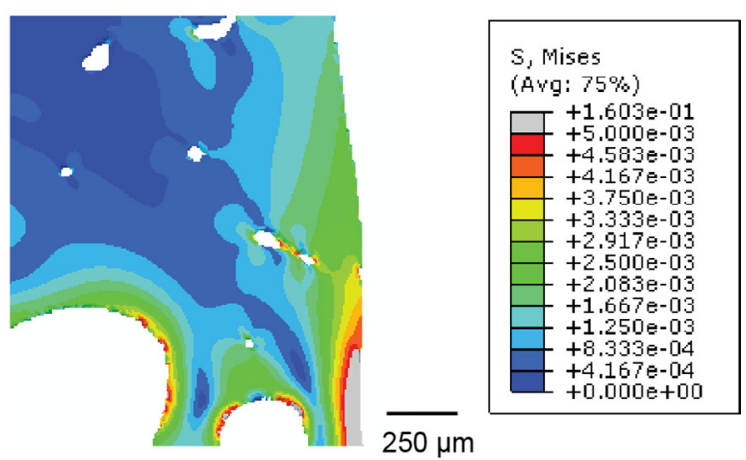

(d)

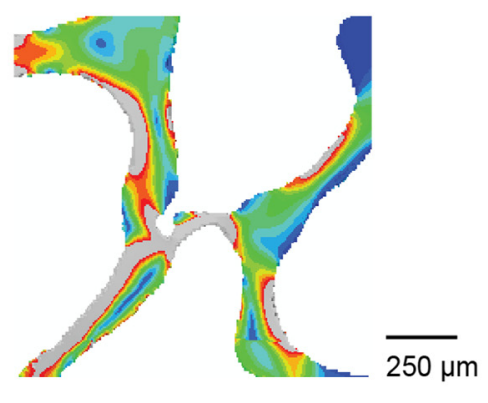

Fig. 4. (a) A microCT image shows the external (top) cortical bone (3.2\% porosity), the middle trabecular bone (55.7\% porosity) and the internal (bottom) cortical bone ( $3.1 \%$ porosity) in the turtle shell. (b) Overview of von Mises stress distributions within the sandwiched cortical-trabecular bone predicted by the microCT-based finite element models. (c) Detailed view of the stress gradients from the cortical bone to trabecular bone. (d) Stress concentrations around the trabecular micro-struts. 
(a)

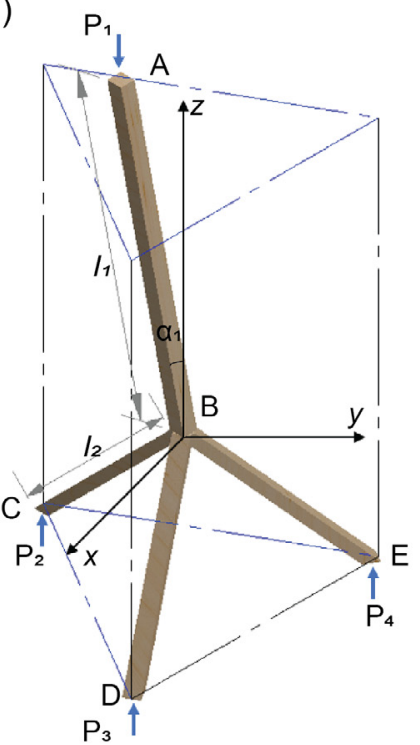

(e)

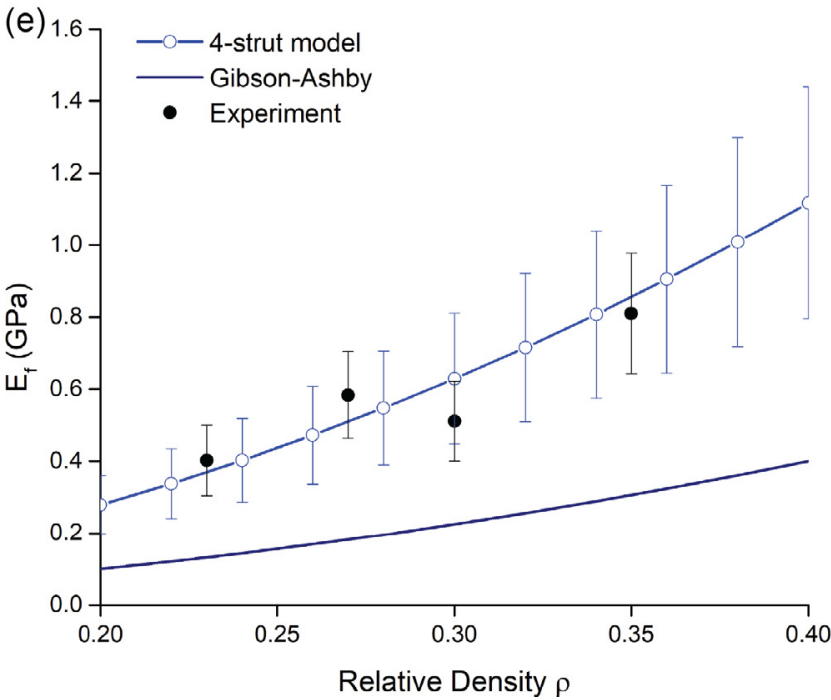

(b)

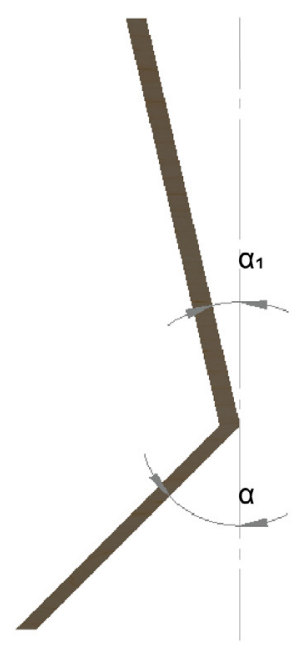

(c)

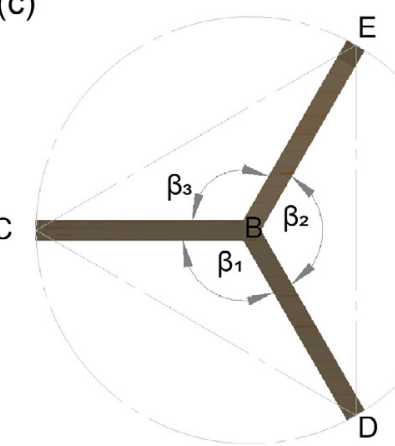

(d)

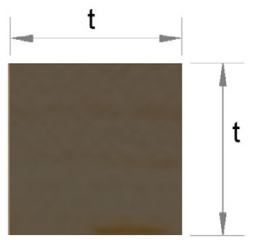

(f) $507-\backsim$ Strut 1 bending, $\alpha=7^{\circ}$

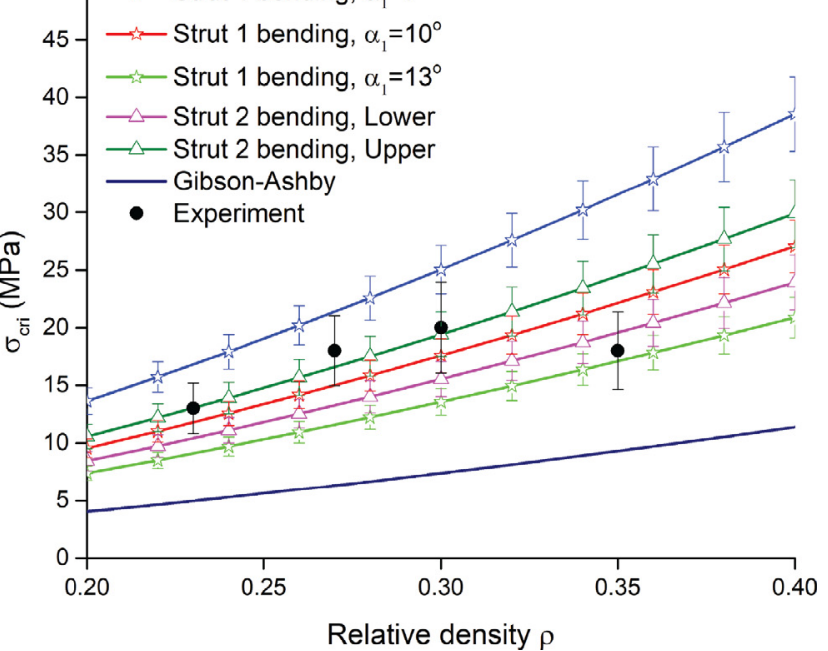

Fig. 5. Schematics of the four-strut foam model: (a) The unit structure with the solid struts; (b) The orientation angles between the struts and the z-axis; (c) Angles between each two struts in the base; and (d) Cross sectional area of each strut. Comparison between predictions from the foam structure models and the experimental measurements (e) Stiffness (f) Plastic collapse strength with the length ratio $\kappa$ ranging from 1.2 to 1.8 .

as shown in Fig. 4b. The magnitudes of the plastic collapse strengths (Fig. 3a and b) were also found to be consistent with estimations (Fig. 5f) from four-struts unit cells that can induce elastic bending and plastic hinges during axial loading along the vertical axis. Furthermore, the Young's moduli of the composite obtained through the stress-strain curves predicted by the finite element models were comparable with the experimental measurements obtained from the compression tests (Fig. 3c). Hence, good agreement was observed between the predicted results and the experiment stress-strain curves in the linear elastic regime (regime 1) (Fig. 3b). The Young's moduli of the sandwiched corticaltrabecular bones decreased with increasing thicknesses of the trabecular bone. This was attributed to the increased porosities of the sandwich structures with thicker trabecular segments.

\subsection{Plastic bending mechanisms}

The elastic deformation of foams under compression consists of elastic compression and elastic bending of struts with different orientations. In the four-strut model [22], the compression stiffness is estimated from the elastic bending of struts in the base because bending of these struts dominates the elastic deformation of the foam. To calculate bending of struts in the base, strut 1 is assumed straight so the its elastic bending is not considered. Eq. (1) shows that the foam structural parameters and the relative density are critical to the compressive stiffness of open cell foams, whereas the Young's modulus of the solid is the only material property that involved. In these models, $\kappa$ was between 1.2 and 1.8 ; $\tau$ was $1.8 ; f$ was $5 / 12 ; \alpha$ was $45^{\circ}$. The yield strength $\sigma_{Y S}$ was $150 \mathrm{MPa}[37,38]$, whereas the Young's modulus of trabecula bone was $2.5 \mathrm{GPa}$.

Predictions obtained from Eq. (1) captured the trends in the measured Young's moduli of the turtle shell (Fig. 5e). For comparison, Young's moduli predicted by the Gibson-Ashby model are also included. These were generally lower than the measured data. By assuming that the bending of struts occurred orthogonally to the loading axis, the Gibson and Ashby model is likely to have a lower-bound stiffness of the open cell foam. In contrast, when we account for the variations in strut length, thickness and orientation, the four-strut model captures the trends in the experimental data, as shown in Fig. 5.

Model predictions of foam strengths are presented in Fig. $5 \mathrm{f}$. In the case of plastic bending of strut 2 in the base, the upper and 
lower bounds were estimated using Eqs. (2) and (3), respectively. For the plastic bending of strut 1, predictions from Eq. (4) were plotted with three inclined angles of strut 1 , i.e., $7^{\circ}, 10^{\circ}$ and $13^{\circ}$. When the inclined angle was less than $7^{\circ}$, the foam strength was determined by plastic bending of struts in the base. In contrast, when the initial including angle was greater than $13^{\circ}$, the foam strength was determined by plastic bending of strut 1 . When the inclined angle of strut 1 was between $7^{\circ}$ and $13^{\circ}$, the stress needed to bend strut 1 fell in the range between the lower and upper bounds of the plastic bending of struts in the base.

Hence, a foam block consisting a large number of structural units, in which there are uncertainties in the orientation of struts will result in a spectrum of foam strengths. The upper and lower bounds were also dependent on the competition between the plastic bending mechanisms in the struts on the base or on top. Furthermore, the model predictions of foam strength with different length ratios were comparable to the measured data (Fig. 5f). Similarly, the strengths predicted by the Gibson-Ashby model $[32,33]$ were lower than the measured strengths (Fig. 5f).

\subsection{Implications}

The implications of the above results are quite significant. First, they show that the turtle shell structures can be idealized as sandwich structures with cortical bone structures on the outside and trabecular bone structures on the inside. Such structures have the capacity to concentrate deformation and stresses within the trabecular section, which enables significant energy absorption during compressive deformation. Subsequently, the mathematical models based on microCT images could be used to understand the mechanical behavior of the sandwiched composites of different biomaterials, such as grass $[39,40]$, beaks $[41,42]$, the snapping shrimp dactyl plunger $[43,44]$ and the whale skeletons $[45,46]$. Findings from these studies might shed essential light into the design and creation of bioinspired composites [47,48]. Furthermore, the trends in the deformation characteristics and the strengths of the trabecular bone segments are well predicted by the four-strut model, which captures the effects of variations in strut length, thickness and orientation that are related to microstructural uncertainties of the turtle shells. The above results also suggest that the four-strut model may be used to guide the design of sandwich porous structures that mimic the properties of the cortical and trabecular bone segments of turtle shells. Such bioinspired structures may enable the design of porous materials that can mimic the energy absorbing capacity of turtle shells under a range of loading conditions.

\section{Conclusions}

This paper presents the results of an integrated experimental, analytical and computational study of the deformation characteristics of turtle shell structures. The sandwiched turtle shell structure is shown to consist of an outer cortical bone, a trabecular bone, and an inner cortical bone structure. The compressive deformation is shown to exhibit three characteristic regimes that includes: an initial linear-elastic regime in which deformation by strut bending; a second deformation regime in which deformation occurs via the propagations of plastic hinges, and a third deformation regime in which densification occurs by plastic collapse prior to final fracture. Finite element simulations of digitized microstructures (obtained via microCT analyses) were found to provide good estimates of the stress-strain behavior and the Young's moduli of sandwich structures consisting of cortical and trabecular bone layers. Furthermore, an analytical four-strut model was found to provide reasonable estimates of the trends in the Young's moduli and the plastic collapse strengths of turtle shell bone structures.

\section{Acknowledgements}

We acknowledge the funding support from World Bank African Center of Excellence, Pan African Materials Institute at The African University of Science and Technology, Worcester Polytechnic Institute, Vermont Technical College, University of Vermont and Princeton University. The authors acknowledge the access to the microCT equipment obtained through the Major Research Instrumentation Program from the National Science Foundation (Grant Number 1429252). Appreciation is also extended to Microscopy Imaging Centers at Princeton University, the University of Vermont and Worcester Polytechnic Institute for assistance with material characterization.

\section{References}

[1] B. Achrai, H.D. Wagner, The turtle carapace as an optimized multi-scale biological composite armor-a review, J. Mech. Behav. Biomed. Mater. 73 (2017) 50-67.

[2] T.R. Lyson, G.S. Bever, T.M. Scheyer, A.Y. Hsiang, J.A. Gauthier, Evolutionary origin of the turtle shell, Curr. Biol. 23 (12) (2013) 1113-1119.

[3] J.E. Moustakas-Verho, G.O. Cherepanov, The integumental appendages of the turtle shell: an evo-devo perspective, J. Exp. Zool. Part B. 324 (B) (2015) 221229.

[4] G.A. Cordero, The turtle's shell, Curr. Biol. 27 (5) (2017) 168-169.

[5] H. Rhee, M. Horstemeyer, Y. Hwang, H. Lim, H. El Kadiri, W. Trim, A study on the structure and mechanical behavior of the Terrapene carolina carapace: pathway to design bio-inspired synthetic composites, Mater. Sci. Eng. C 29 (8) (2009) 2333-2339.

[6] G. Rivera, C.T. Stayton, Finite element modeling of shell shape in the freshwater turtle Pseudemys concinna reveals a trade-off between mechanical strength and hydrodynamic efficiency, J. Morphol. 272 (10) (2011) 1192-1203.

[7] D.L. Hu, K. Sielert, M. Gordon, Turtle shell and mammal skull resistance to fracture due to predator bites and ground impact, J. Mech. Mater. Struct. 6 (9) (2011) 1197-1211.

[8] W. Zhang, C. Wu, C. Zhang, Z. Chen, Numerical study of the mechanical response of turtle shell, J. Bionic. Eng. 9 (3) (2012) 330-335.

[9] W. Zhang, C. Wu, C. Zhang, Z. Chen, Microstructure and mechanical property of turtle shell, Theor. Appl. Mech. Lett. 2 (1) (2012).

[10] Y. Shelef, B. Bar-On, Surface protection in bio-shields via a functional soft skin layer: lessons from the turtle shell, J. Mech. Behav. Biomed. Mater. 73 (2017) 68-75.

[11] B. Achrai, H.D. Wagner, Micro-structure and mechanical properties of the turtle carapace as a biological composite shield, Acta Biomater. 9 (4) (2013) 5890-5902.

[12] C.T. Stayton, Biomechanics on the half shell: functional performance influences patterns of morphological variation in the emydid turtle carapace, Zoology 114 (4) (2011) 213-223.

[13] C. Vega, C.T. Stayton, Dimorphism in shell shape and strength in two species of emydid turtle, Herpetol. 67 (4) (2011) 397-405.

[14] T. Tan, N. Rahbar, S. Allameh, S. Kwofie, D. Dissmore, K. Ghavami, W. Soboyejo, Mechanical properties of functionally graded hierarchical bamboo structures, Acta Biomater. 7 (10) (2011) 3796-3803.

[15] M. Chen, N. Hu, C. Zhou, X. Lin, H. Xie, Q. He, The hierarchical structure and mechanical performance of a natural nanocomposite materials: The turtle shell, Colloids Surf. A Physicochem. Eng. Asp. 520 (2017) 97-104.

[16] K. Balani, R.R. Patel, A.K. Keshri, D. Lahiri, A. Agarwal, Multi-scale hierarchy of Chelydra serpentina: microstructure and mechanical properties of turtle shell, J. Mech. Behav. Biomed. Mater. 4 (7) (2011) 1440-1451.

[17] P.M. Magwene, J.J. Socha, Biomechanics of turtle shells: how whole shells fail in compression, J. Exp. Zool. Part A 319 (A) (2013) 86-98.

[18] I.H. Chen, W. Yang, M.A. Meyers, Leatherback sea turtle shell: a tough and flexible biological design, Acta Biomater. 28 (2015) 2-12.

[19] B. Achrai, B. Bar-On, H.D. Wagner, Bending mechanics of the red-eared slider turtle carapace, J. Mech. Behav. Biomed. Mater. 30 (2014) 223-233.

[20] B. Achrai, H.D. Wagner, The red-eared slider turtle carapace under fatigue loading: the effect of rib-suture arrangement, Mater. Sci. Eng. C 53 (2015) 128-133.

[21] R. Damiens, H. Rhee, Y. Hwang, S. Park, Y. Hammi, H. Lim, M. Horstemeyer Compressive behavior of a turtle's shell: experiment, modeling, and simulation, J. Mech. Behav. Biomed. Mater. 6 (2012) 106-112.

[22] J. Zhou, Mechanical Behavior of Open Cell Aluminum Foams PhD thesis, Princeton University, Princeton, NJ, 2004.

[23] J. Zhou, Z. Gao, A. Cuitino, W. Soboyejo, Effects of heat treatment on the compressive deformation behavior of open cell aluminum foams, Mater. Sci. Eng. A 386 (2004) 118-128. 
[24] H. Rhee, M.T. Tucker, W.R. Whittington, M.F. Horstemeyer, H. Lim, Structureproperty responses of bio-inspired synthetic foams at low and high strain rates, Sci. Eng. Compos. Mater. 22 (4) (2015) 365-373.

[25] N. Jongpairojcosit, P. Jearanaisilawong, Mechanical properties and numerical simulation of Sulcata tortoise carapace, J. Mech. Behav. Biomed. Mater. 72 (2017) 261-267.

[26] X. Zhang, Z. Cai, W. Li, M. Zhu, Understanding hydration effects on mechanical and impacting properties of turtle shell, J. Mech. Behav. Biomed. Mater. 78 (2018) 116-123.

[27] N. Rahbar, M. Jorjani, C. Riccardelli, G. Wheeler, I. Yakub, T. Tan, W. Soboyejo, Mixed mode fracture of marble/adhesive interfaces, Mater. Sci. Eng. A 527 (2010) 4939-4946.

[28] T. Tan, N. Rahbar, A. Buono, G. Wheeler, W. Soboyejo, Sub-critical crack growth in adhesive/marble interfaces, Mater. Sci. Eng. A 528 (2011) 3697-3704.

[29] V.L. Ferguson, S.E. Olesiak, Nanoindentation of Bone, The Handbook of Nanoindentation with Biological Applications, Pan Stanford, Singapore, 2010.

[30] W. Soboyejo, Mechanical Properties of Engineered Materials, CRC Press, 2002.

[31] W. Soboyejo, J. Zhou, S. Allameh, Multi-scale mechanical behavior of metallic foams: From struts to foams, ICF11, Italy, 2005.

[32] L.J. Gibson, M.F. Ashby, Cellular Solids: Structure and Properties, Cambridge University Press, 1999.

[33] L.J. Gibson, M.F. Ashby, B.A. Harley, Cellular Materials in Nature and Medicine, Cambridge University Press, 2010.

[34] T.A. Owoseni, Bioinspired Design Master Thesis, The African University of Science and Technology, Nigeria, 2013.

[35] M. Kay, R. Young, A. Posner, Crystal structure of hydroxyapatite, Nature 204 (1964) 1050.

[36] M. Mucalo, Hydroxyapatite (HAp) for Biomedical Applications, Elsevier, 2015.

[37] D. Taylor, J.G. Hazenberg, T.C. Lee, Living with cracks: damage and repair in human bone, Nat. Mater. 6 (2007) 263.
[38] D. Taylor, Fracture and repair of bone: a multiscale problem, J. Mater. Sci. 42 (2007) 8911-8918.

[39] J.F.V. Vincent, Strength and fracture of grasses, J. Mater. Sci. 26 (1991) 19471950.

[40] J.F.V. Vincent, The mechanical design of grass, J. Mater. Sci. 17 (1982) 856-860.

[41] R.S. Fecchio, Y. Seki, S.G. Bodde, M.S. Gomes, J. Kolososki, J.L. Rossi Jr, M.A. Gioso, M.A. Meyers, Mechanical behavior of prosthesis in Toucan beak (Ramphastos toco), Mater. Sci. Eng. C 30 (2010) 460-464.

[42] N. Lee, M.F. Horstemeyer, H. Rhee, B. Nabors, J. Liao, L.N. Williams, Hierarchical multiscale structure-property relationships of the red-bellied woodpecker (Melanerpes carolinus) beak, J. R. Soc. Interface 11 (2014) 20140274.

[43] P. Alam, I. Sanka, L.P. Alam, S. Wijaya, E. Sintya, N.S.N. Handayani, A. RiveroMüller, The snapping shrimp dactyl plunger: a thermomechanical damagetolerant sandwich composite, Zoology 126 (2018) 1-10.

[44] M. Versluis, B. Schmitz, A. von der Heydt, D. Lohse, How snapping shrimp snap: through cavitating bubbles, Science 289 (2000) 2114-2117.

[45] P. Alam, S. Amini, M. Tadayon, A. Miserez, A. Chinsamy, Properties and architecture of the sperm whale skull amphitheatre, Zoology 119 (2016) 42 51.

[46] B. Wang, T.N. Sullivan, A. Pissarenko, A. Zaheri, H.D. Espinosa, M.A. Meyers, Lessons from the ocean: whale baleen fracture resistance, Adv. Mater. 31 (2019) 1804574

[47] Z. Hu, V.K. Gadipudi, D.R. Salem, Topology optimization of lightweight lattice structural composites inspired by cuttlefish bone, Appl. Compos. Mater. 26 (2019) 15-27.

[48] L.S. Dimas, M.J. Buehler, Modeling and additive manufacturing of bio-inspired composites with tunable fracture mechanical properties, Soft Matter 25 (2014) 4436-4442. 